\title{
A INFÂNCIA, OS 'LUGARES DA MEMÓRIA' E A RECEPÇÃO NAS CRÔNICAS DE MILTON HATOUM
}

\author{
Ana Carolina da Conceição Figueiredo \\ Mestranda em Estudos Literários pela Universidade do Estado do Rio de Janeiro (UERJ) \\ karolfigueiredo@hotmail.com
}

\section{RESUMO}

Este trabalho tem por objetivo pensar a infância, 'os lugares da memória' e a recepção a partir das análises das crônicas "Elegia para todas as avós", "Espingarda e um livro de papai Noel", "Prece de um amazonense em São Paulo e Brasília: trauma e reconciliação", de Milton Hatoum, publicadas na Revista Eletrônica Terra Magazine entre 2006 e 2010, com base no pensamento de Silvia Molloy (2003, p. 14), a qual visa compreender "quais são as fabulações a que recorre uma escrita de si em um certo espaço, em um certo tempo e em uma certa linguagem." Ademais, tomaremos a cidade de Brasília como um lugar da memória recorrente na crônica "Exílio". Por fim, discutiremos o processo de leitura das crônicas a partir da interação texto e leitor. As nossas considerações sobre a recepção desses textos de Milton Hatoum serão fundamentadas nas abordagens teóricas Iser (1984), Jauss (1994) e Jouve (2002).

Palavras-chave: Infância, lugares da memória, Recepção, Terra Magazine, Milton Hatoum.

\section{ABSTRACT}

This work aims at thinking about childhood, 'the places of memory' and the reception analysing the chronicles "Elegia para todas as avós", "Espingarda e um livro de papai Noel", "Prece de um amazonense em São Paulo e Brasília: trauma e reconciliação", by Milton Hatoum, published in Eletronic Magazine Terra Magazine between 2006 and 2010. This study is based on the conceptions of Silvia Molloy (2003, p. 14) which is understood by "the styles of the fables and how they are written according to place, year and language. Moreover, we have the city Brasília as a place of memory that is presented in the chronicle "Exilio". We discuss the process of reading the chronicle by analyzing the interaction between the text and the reader. Our considerations about the reception of these texts by Miltom Hatoum are based on Iser (1984), Jauss (1994) e Jouve (2002).

Keywords: childhood, places of memory, reception, Terra Magazine, Milton Hatoum. 


\section{Introdução}

Talvez o trabalho do ficcionista seja movido por um diálogo tenso entre a memória e o tempo presente. Desse diálogo surgem as palavras com seus personagens, histórias, romances ou relatos que reinventam a vida. Milton Hatoum

Esta epígrafe retirada da crônica "Escrever em qualquer lugar", de Milton Hatoum nos direciona para pensarmos o texto enquanto registro não só de um tempo presente, mas também como um espaço onde se fazem fabulações movidas por um "eu" narrador, personagem de sua própria história. As composições textuais de teor autobiográfico presente nas crônicas "Elegia para todas as avós", "Espingarda e um livro de papai Noel", “Prece de um amazonense em São Paulo" e "Brasília: trauma e reconciliação", de Milton Hatoum, podem ser pensadas conforme Silvia Molloy (2003, p. 19): "não dependem de acontecimentos, mas da articulação destes eventos armazenados na memória e reproduzidos através de rememoração e verbalização".

A partir dessas considerações, o presente artigo tem por objetivo, em primeiro lugar, refletir sobre a infância como recurso memorialístico agregados nas crônicas "Elegia para todas as avós" e em "Espingarda e um livro de papai Noel" de Milton Hatoum. Em seguida, trilharemos ‘os lugares da memória' desenhados em “Prece de um amazonense em São Paulo" e "Brasília: trauma e reconciliação", ambas publicadas na Terra Magazine. Por último, discutiremos o papel do texto e do leitor no processo de constituição de sentido dos textos Hatouniano. 


\section{A infância como recurso memorialístico em "Elegia para todas as avós" e em "Espingarda e um livro de papai Noel"}

Ler as crônicas de Milton Hatoum, publicadas na Revista eletrônica Terra Magazine durante o período de 2006 a 2010, é aventurar-se em estruturas textuais híbridas e conhecer discussões que abordam temas como violência, desmatamento, educação, corrupção política, preconceito, entrevista, infância e memória. Quando percorremos as crônicas podemos ver o modo como o autor trabalha a linguagem, e a forma particular como manuseia as palavras projeta para os leitores uma construção textual que, ao mesmo tempo, imbrica escolhas de conteúdo, forma e linguagem em uma prática de escrever que busca constantemente organizar os signos linguísticos de forma a configurar um campo semântico específico que chamaremos, genericamente, de "poética de autor".

Esse exercício de aprimoramento das palavras reflete sobre seu trabalho como um todo, e no caso de sua produção como cronista, requer de nós, leitores, um método de leitura e avaliação diverso do trabalho que o amazonense efetua com seus romances, por exemplo. Por isso, o estudo dessas composições narrativas, como um todo, seja para verificar quais as temáticas desenvolvidas por Hatoum ou a forma como estrutura o texto de encomenda, que é a crônica, motivou este estudo acerca das crônicas publicadas por ele na Terra Magazine.

Pensar no entrelaçamento dos signos e nas composições temáticas nos direcionam para reflexões em torno dos elementos memorialísticos presentes em algumas das crônicas do TM. Nesse sentido, queremos mencionar que crônicas como "Elegia para todas as avós" (HATOUM, 2008e) e "Espingarda e um livro de papai Noel" 
(HATOUM, 2007n) trazem breves recortes da memória de infância. Esse trajeto pelos caminhos da autobiografia relaciona-se não à ideia de tentar descobrir não "tanto o que o "eu" está tentando fazer quando escreve "eu", mas, mais modestamente, quais são as fabulações a que recorre uma escrita de si em um certo espaço, em um certo tempo e em uma certa linguagem" (MOLLOY, 2003, p. 14).

Existem, ao longo de "Elegia para todas as avós", comentários e relatos em primeira pessoa referentes às avós, "seres inesquecíveis." Diferentemente da avó desalmada retratada no conto $A$ incrível e triste história da Cândida Erêndira e sua avó desalmada (1972), de Gabriel Garcia Márquez, a crônica aponta as avós como mulheres poderosas e "afetuosas além da conta e dispostas a darem tudo pelos netos" (HATOUM, 2008e). Além disso, menciona o papel significativo da avó-matriarca por construir um legado e a memória do clã, afirmado, por exemplo, a partir do relato testemunhal de uma índia wanano, da região do Rio Negro: "sua avó quase centenária reunia os netos para contar histórias de sua tribo. Ela nos ensinou os mitos de origem, disse a neta. Mitos esquecidos pelos mais jovens. Agora quero pôr tudo o que ela me contou num livro" (HATOUM, 2008).

Uma avó também está relacionada às recordações da infância, que habitam a imaginação da criança. De certo modo, algumas avós, mesmo ausentes, conseguem existir seja nas lembranças guardadas, nas fotografias, seja nas histórias contadas pelos pais e parentes. Assim, um narrador em primeira pessoa relembra histórias que o pai contava sobre a bisavó, Salma: "Salma, minha bisavó paterna, que eu não conheci [... deixava a turma de crianças soltar as aves, brincar com elas, engaiolá-las, fazer o diabo com os bichinhos. [...] Salma chorou quando meu pai, ainda jovem, migrou para o Brasil, onde viveu mais de meio século" (HATOUM, 2008). Desse modo, "Elegia para todas as 
avós" enquadra-se dentro do tipo de elegia sentimental, tendo em vista que marca o leitor pelo tom nostálgico e por exaltar a figura da avó.

Ao discorrer em tom ensaístico sobre a avó desalmada, personagem do conto colombiano, e mediante as considerações sobre a figura da avó, mulher que habita a imaginação da infância, ressalta que: "Até mesmo uma criança que não conheceu sua avó, constrói aos poucos uma imagem dessa mulher ausente, evocada com saudade nas conversas domingueiras e admirada nas fotografias dos álbuns de família." (HATOUM, 2008). Desse modo, a memória consiste em tema da crônica e em matéria que constrói a história documental, neste caso, imagem de uma pessoa da infância retomada na memória adulta do "eu". Nas palavras de Silvia Molloy (2003, p. 21) "as referências à infância aparecem, ou são vistas prolepticamente, como antevendo as aquisições do adulto, ou são usadas por seu valor documental".

A recordação da avó no tempo da infância ganha forma na escrita de si e, assim, resulta em valor documental, porque é na linguagem e na escrita que essas fabulações se concretizam como autobiografias. A infância, em "Elegia para todas as avós", consiste na representação satisfatória do passado, pois “a vida é sempre, necessariamente, uma história; história que contamos a nós mesmos como sujeitos, através da rememoração." (MOLLOY, 2003, p. 19).

Se, em "Elegia para todas as avós", o "eu" da narrativa revive a infância a partir da avó matriarca, por outro lado, em "Espingarda e um livro de papai Noel", o leitor se depara com recordação de presentes de natal: "Na minha infância ganhei também bolas de futebol, uma bicicleta, um teco-teco de madeira e revistas em quadrinhos; Mandrak Cavaleiro Negro, Cavaleiro Fantasma... Nada de brinquedo elétrico, muito menos eletrônicos; nenhum urso tocando tambor" (HATOUM, 2007). 
O "eu" narrador relata também as três espingardas da infância dos tios que ele herdou de presente quinze anos depois, quando os tios já eram homens: "as quatro espingardas apareceram debaixo da minha cama. Nenhuma funcionava; pareciam frutas descascadas e abandonadas. Soube que um dos tios - o caçula - havia feito essa brincadeira tardia de papai Noel." (HATOUM, 2007). Sabe-se que, de certo modo, a recordação dos brinquedos também traz consigo uma memória coletiva, compartilhada, relacionada aos momentos em família e as comemorações natalinas que permanecem fixadas em nossa memória adulta.

No entender de Vincent Jouve (2002, p. 117), “Ler, de certa forma, é reencontrar as crenças e, portanto, as sensações da infância. A leitura, que outrora ofereceu para nosso imaginário um universo sem fim, ressuscita esse passado cada vez que, nostálgico, lemos uma história" Assim, as recordações do "eu" narrador / personagem inscritas nessas duas crônicas atuam como gatilhos, que levam o leitor a reviver o seu passado. Isso acontece porque o texto suscita experiências particulares e libertadoras, uma vez que a criança adormecida, em nós, renasce ao se deparar com as cenas da infância.

\section{Trilhando "os lugares da memória" em "Prece de um amazonense em São Paulo" e em "Brasília: trauma e reconciliação"}

Na crônica' "Prece de um amazonense em São Paulo" (HATOUM, 2007), Milton Hatoum esboça o Amazonas, sua terra natal, como "o lugar da memória", pois refere-se à região como lugar de refúgio e proteção. As recordações bem desenhadas da cidade de origem surgem grafadas nos versos da crônica-poema, quando o eu lírico, ao se ver no caos da metrópole paulista, clama ao Espírito do Amazonas amparo e proteção: “Espírito 
do Amazonas, me ilumina, / e sobre o caos desta metrópole, / conserva em mim ao menos um fio / do que fui na minha infância" (HATOUM, 2007). Clama por proteção, porque deseja conservar as lembranças, as memórias do tempo da infância, época em que foi feliz por habitar a sua terra natal e por não viver no caos, como na cidade de São Paulo.

Notamos os sentimentos de medo e de melancolia nos versos: "Não quero ser pássaro em céu de cinzas / nem amargar noites de medo / nas marginais de um rio que não renasce" (HATOUM, 2007). Embora o sujeito tenha consciência de que nasceu para ser livre, conquistar e alcançar os seus sonhos, pois saiu da terra de origem com visão de progresso e crescimento, ele fica sem esperança ao se deparar com as dificuldades de adaptação em uma metrópole. Além disso, podemos inferir que o fragmento "nas marginais de um rio que não renasce" alude também à discussão sobre os grupos considerados subalternos, os quais vivem à margem, presos a um céu de cinzas, ou seja, sem voz, sem visibilidade.

A imagem do Amazonas, vítima da ganância de políticos corruptos, "que se lixam para o povo brasileiro" (HATOUM, 2009), está presente na estrofe "Amazonas: / Tua ânsia de infinito ainda perdura? / Ou perdi precocemente toda esperança? Os que te queimam, impunes, / têm olhos de cobre, / mãos pesadas de ganância" (HATOUM, 2007). Esta imagem é evocada também em crônicas como "Amazônia: um pouco antes do fim" (HATOUM, 2008) e "Ainda Amazônia" (HATOUM, 2008). Com isso, notamos a temática da corrupção e do desmatamento como assunto recorrente nas crônicas da Terra Magazine. No caso do poema, a voz poética coloca em destaque através dos vocábulos "olhos de cobre" e "mãos pesadas de ganância" o interesse dos políticos pelo dinheiro. 
Nas estrofes finais, o sujeito poético evoca o espírito amazonense para que ele não o deixe em São Paulo, pois as memórias das suas raízes configuram-se como instrumentos de forças e de ânimo contra os "pesadelos que incendeiam o mundo" (HATOUM, 2007). O trecho "Se o Brasil te conhecesse / antes do fim que se aproxima, salvaria tua beleza? Teus seres desencantados? Entenderia a ciência tua infinita riqueza?" (HATOUM, 2007) nos remete à crônica "Amazônia: um pouco antes do fim" (HATOUM, 2008), tendo em vista que, quando a voz poética constrói essas perguntas-problemas, coloca em evidência a riqueza cultural da Amazônia e reitera as particularidades geográficas, sociais, culturais, simbólicas.

Desse modo, entendemos que ele revive, diante dos transtornos encontrados em São Paulo, a sua própria autoimagem amazonense, mas isso só foi possível porque trazia as experiências "armazenadas na memória e reproduzido através de rememoração e verbalização" (MOLLOY , 2003, p. 19). O mesmo processo de recordação acontece, quando, em "Brasília: trauma e reconciliação" (HATOUM, 2007) o "eu" narrador rememora momentos ruins vividos em Brasília, quando recebeu o convite do Correio Braziliense para escrever um texto sobre o período que morou na capital. Brasília é um lugar da memória, porque guarda vivências do período da ditadura, momento de repressão e censura. A imagem do espaço geográfico da capital brasileira também permanecia em suas lembranças, assim como o colégio onde estudou:

Revi alguns amigos e com eles relembrei as noitadas no Beirute, as viagens-relâmpagos para uma cidade-satélite, o movimento estudantil, a leitura disciplinada de Sartre e Graciliano Ramos, o último amor platônico da juventude, o primeiro ato da loucura transgressora dos anos 60 , em que a experiência politica era inseparável de outras vivencias sensoriais e corporais (HATOUM, 2007). 
Dessa forma, Brasília consiste em um "lugar da memória" que relembra acontecimentos marcantes, mas que também possibilitou ao narrador-personagem compreender o quanto amadureceu e as transformações pelas quais passou 32 anos depois - "quando observei a cidade com outro olhar, como alguém revê uma pessoa que amadureceu e que te olha sem mágoa, rancor ou ressentimento. Em cada super-quadra, o barro de antes se tornara um gramado com um quintal magnífico" (HATOUM, 2007).

A cidade de Brasília aparece como "lugar da memória" em crônicas e no romance A noite da espera (2017), para exemplificar. As menções à capital do Brasil podem ser encontradas na crônica "Exílio", publicada no livro Um solitário à espreita (2013). "Exílio" (HATOUM, 2013, p. 53-54) traz para o leitor uma imagem de Brasília e tece relatos sobre as lembranças dos acontecimentos vividos pelo "eu" narrador na cidade. O cronista conta momentos em que foi preso juntamente com o amigo M.A.C, que continuou preso e foi torturado.

M.A.C. decidiu ir a pé até a rodoviária: comeria um pastel e seguiria para a W3. Numa tarde assim, seca e ensolarada, dava vontade de caminhar, mas preferi pegar o ônibus uma hora antes do combinado: saltaria perto do hotel Nacional, desceria a avenida contornando as casas geminadas da W3. A cidade ainda era estranha para mim: espaço demais para um ser humano, a superfície de barro e grama se perdia no horizonte do cerrado. [...] A dispersão e a correria continuavam: o mais prudente era ficar sentado no gramado da 302 ou da 307 e assistir ao bate-bola das crianças [...] A rua e quadra comercial foram cercadas como num pesadelo, tentar fugir ou reagir seria igualmente desastroso. Depois de chutes de empurrões, eu e meu colega rumamos para o desconhecido (HATOUM, 2013, p. 53-54).

Essa crônica estrutura alguns fatos da vida do próprio autor, que afirma ter saído

“de casa aos 15 anos e me mudei para Brasília e depois para São Paulo [...] porque Eu queria sair da província, queria me libertar. E fui detido pela polícia. [...] Passei um dia e 
uma noite preso, por participar de uma passeata." Desse modo, pode-se dizer que essa crônica tem um cunho de autobiografia, embora em certos momentos a imaginação prevaleça, logo, "Exílio" está na fronteira entre real, fictício e imaginário. Ao escrever sobre um acontecimento de sua vida, o autobiografo tenta "dar voz àquilo que não fala, de trazer o que está morto à vida, dotando-o de uma máscara textual" (MOLLOY, 2003, p. 13).

\section{Recepção do leitor: lendo a infância e os lugares da memória}

As fabulações presentes em "Exílio" abordam certas referências, as quais serão reconstruídas e preenchidas quando entrarem em contato com o horizonte de expectativa do leitor. Segundo Iser, isso acontece porque "o texto ficcional contém muitos fragmentos identificáveis da realidade, que, através da seleção, são retirados tanto do contexto sócio-cultural, quanto da literatura prévia ao texto." (In: Costa Lima, 1983, p. 400). Esse efeito ilusório do real poderá levar o leitor a relacionar os eventos descritos na narrativa com a vida do autor. Isso ocorre porque "Exílio" e "Brasília: trauma e reconciliação" são narrativas que apresentam em sua estrutura lances memorialísticos.

A infância e os lugares da memória presentes nas crônicas de Hatoum impactam o leitor ao entrar em seu horizonte de expectativa, tendo em vista que texto e leitor possuem, cada um, uma parte de cooperação no processo de leitura. Sobre o leitor, Hans Robert Jauss, teórico da Estética da Recepção, o compreende como uma categoria social, com um ser que possui vivência de mundo, experiências pessoais, um olhar histórico e social, condições afetivas e conhecimentos linguísticos e literários. Jauss chama toda essa bagagem que o leitor aciona para entender o texto de "Horizonte de expectativas." Nesse 
sentido, a leitura se desenvolve na fusão do horizonte de expectativas do leitor com o horizonte de expectativas do texto. De acordo com Jauss:

Ademais, a obra que surge não se apresenta como novidade absoluta num espaço vazio, mas, por intermédio de avisos, sinais visíveis e invisíveis, traços familiares ou indicações implícitas, predispõe seu público para recebê-la de uma maneira bastante definida. Ela desperta a lembrança do já lido, enseja logo de início expectativas quanto a "meio e fim", conduz o leitor a determinada postura emocional e, com tudo isso, antecipa um horizonte geral da compreensão vinculado, ao qual se pode, então - e não antes disso - , colocar a questão acerca da subjetividade da interpretação e do gosto dos diversos leitores ou camadas de leitores (JAUSS, 1994, p. 51).

No âmbito da estrutura do texto encontra-se uma organização pré-estruturada, ou seja, saberes, conhecimentos inscritos no texto, para que o leitor consiga compreender, logo, experienciar a leitura.

Sob essas perspectivas, compreende-se que a leitura envolve os processos relacionados à interação texto e leitor. Nesse sentido, pode-se comentar com as palavras de Jouve (2002, p. 17), segundo o qual "A leitura é uma atividade complexa, plural, que se desenvolve em várias direções." Isso acontece pois o texto literário é constituído não apenas de um entrelaçamento de signos, que se originaram das ideias de um ser empírico, ou seja, de seus pensamentos, vivências ou conhecimento de mundo. A leitura, para ter sentido e ganhar vida, depende do encontro com o leitor, um ser pensante, com uma vivência cultural e subjetiva. O modo como esse leitor interpreta as informações veiculadas no texto dependerá também da composição, quer dizer, do modo como os signos estão estruturados. Em outras palavras, do que a obra lhe apresenta na sua estrutura. 
Essas referências lançadas na inscrição da narrativa, o modo como os signos são articulados e preenchem a estrutura textual, como também os conhecimentos que o texto exige do leitor, são chamados de "leitor implícito", que se estrutura visando causar um efeito no leitor. O horizonte de expectativas implícito da obra configura-se, assim, como os conhecimentos, saberes prévios que o leitor precisa possuir para compreender a história narrada. Como mencionado anteriormente, a recepção ocorre quando há a fusão dos horizontes implícitos da obra com o horizonte do leitor, acontecendo assim o preenchimento dos vazios, e levando o leitor à compreensão da obra.

Esse modo do texto se estruturar requer um maior esforço de abstração do leitor, considerando que "a leitura apresenta-se, pois, como uma atividade de antecipação, de estruturação e interpretação." (Jouve, 2002, p. 18). Assim, o leitor dessas crônicas acaba tendo que diminuir a sua velocidade de leitura, para que consiga compreender os sentidos e as referências assinaladas. Ao frear a progressão da leitura, o leitor focaliza a interpretação em prol do regime de compreensão. Sobre esse tipo de leitura, Barthes (apud, Jouve, 2002, p. 19) afirma que “[...] não deixa passar nada; ela pesa, gruda ao texto, lê se assim se pode dizer, com aplicação e ânimo, enxerga em cada ponto do texto o assíndeto que corta as linguagens- e não a história: não é a extensão (lógica) que a cativa, o desfolhamento das verdades, mas o folhear do sentido." Além disso, certas questões serão omitidas pelo texto, as quais deverão ser elaboradas e reconstruídas no desenrolar dos acontecimentos.

O leitor criará outras hipóteses interpretativas. Além disso, ao considerar o espaço que o texto deixa para o leitor, este terá de completar as demais informações em seu imaginário e tomar como objetos de auxílio a ordem das ações e a linguagem simbólica. Sobre esse aspecto do texto literário, Jouve (2002, p. 63) afirma que: "Como as 
personagens, o espaço e a situação não podem ser descritos inteiramente, o leitor completará a narrativa na sua imaginação segundo aquilo que lhe parece verossímil." Em outras palavras, caberá ao leitor reunir toda a significação da obra.

\section{Considerações finais}

As reflexões sobre a infância e 'os lugares da memória', temas caros articulados na composição das crônicas, apontam para breves relatos autobiográficos que podem ter relação com algum momento da vida do autor. Notamos que a cidade de Brasília é cenário, muitas vezes, de algumas crônicas de Hatoum, assim como aparece também no novo romance $A$ noite da espera (2017). As referências à capital do Brasil configuram-se, de certa forma, como retorno a um passado que ainda se encontra bem presente pelo aspecto marcante dos acontecimentos e pelo moldar das experiências e vivências.

Essas questões que compõem as crônicas apontam para a multiplicidade da literatura brasileira contemporânea, a qual "se revela na linguagem, nos formatos, na relação que se busca com o leitor [...] são múltiplos tons e tema" (RESENDE, 2008, p. 18). Uma relação interacional com o leitor que resulta em funções diferentes para o desenrolar da leitura, isto é, o texto elabora um estrutura narrativa e temática que poderá confundir o leitor, o qual aciona todos o conhecimento para compreender o texto.

\section{Referências}

HATOUM, Milton. Exílio. In: . Um solitário à espreita. São Paulo: Companhia das Letras, 2013. 
Prece de um amazonense em São Paulo. (28 nov. 2007a). Disponível em: <http://terramagazine.terra.com.br>. Acesso em: 29 nov. 2008.

Elegia para todas as avós. (15 dez. 2008b). Disponível em:

<http://terramagazine.terra.com.br>. Acesso em: 20 ago. 2009.

. Espingardas e um livro de Papai Noel. (5 dez. 2007c). Disponível em:

<http//:terramagazine.com.br>. Acesso em: 20 ago. 2009.

Milton. Brasília, trauma e reconciliação. (2 jul. 2007d). Disponível em:

<http://terramagazine.terra.com.br>. Acesso em: 27 nov. 2007.

. O arquiteto que não fui. (13 ago. 2008e). Disponível em:

<http://terramagazine.terra.com.br>. Acesso em: 27 nov. 2008.

Pestes brasileiras. (17 de ago de 2009f.). Disponível em:

<http://terramagazine.terra.com.br>. Acesso em: 27 nov. 2008.

Milton. Entrevista ao site Veja Abril, outubro de 2017. Disponível em:

<https://veja.abril.com.br/revista-veja/o-que-nao-vivi-imaginei/>. Acesso em: 8 set. 2018.

ISER, Wolfgang. Os atos de fingir ou o que é fictício no texto ficcional. In: LIMA, Luiz Costa. (org.). Teoria da literatura em suas fontes. 2. ed. Rio de Janeiro: Francisco Alves, 1984. v. 2.

JAUSS, Hans Robert. A história da literatura como provocação à teoria literária. Tradução Sérgio Tellaroli. São Paulo: Ática, 1994.

JOUVE, Vincent. A leitura. Tradução Brigitte Hervot. São Paulo: Editora UNESP, 2002.

MOLLOY, Silvia. Vale o escrito. A escrita autobiográfica na América Hispânica. Chapecó: Argos, 2003.

Recebido em 09 de janeiro de 2019.

Aceite em 11 de maio de 2019.

\footnotetext{
'Nomeamos esta crônica como crônica-poema, porque, embora seja nitidamente um poema, o autor a enquadra dentro do gênero crônica.
} 